\title{
Object Detection using K-Means Clustering - A Research
}

\author{
Madhura P Divakara, Keerthi V Trimal, Adithi Krishnan, Karthik V
}

\begin{abstract}
Clustering is an unsupervised machine learning technique and the task is to group a set of objects in such a way that objects in the same group are more similar to each other than those in other groups. There are different clustering techniques, each with its own advantages and disadvantages. The K-means clustering algorithm is our main focus in this paper. K-means is mostly used when there is a large number of unlabeled data. The difficulties in the path of K-means clustering are a) Different initial points can lead to different final clusters. b) It does not work with clusters of different sizes and densities. $c$ ) With the global cluster, it does not work well and is difficult to determine K Value. Our main aim is to try and modify the K-means clustering algorithm to get rid of the above-mentioned drawbacks.
\end{abstract}

Keywords: K-means clustering, Machine Learning, cluster, object detection.

\section{INTRODUCTION}

Object detection is a computer technology for computer vision and image processing that detects instances of semantic objects in digital images and videos of certain classes (such as humans, buildings or cars). Well researched object detection domains include facial detection and pedestrian detection. Object detection has applications in many areas of computer vision, including video surveillance and image collection. It is widely used in computer vision tasks like face detection, face recognition, co-segmentationof video objects. It is also used to track objects, e.g. to track a ball during a football match, to track a cricket bat's movement, to track a person in a video.

Currently, clustering algorithms such as function clustering, k-means clustering, hierarchical clustering, etc. are used for object detection.K-means clustering is popularly referred to as Lloyd's algorithm. K-means clustering has several disadvantages, such as data scaling, highly sensitive to initial seeds and noise, data order, unable to handle non-convex clusters of varying density and size. Hierarchical clustering also has disadvantages such as greater time complexity, previous steps, vague termination criteria, etc.

Many k-means clustering methods have been proposed and introduced in recent times, but some still need to fix the minimum cluster size, some scale poorly on high-dimensional problems, etc. Our goal is to develop an

Revised Version Manuscript Received on August 19, 2019.

Madhura P Divakara, Department of Computer Science and Engineering, Vidyavardhaka College of Engineering, Mysuru, Karnataka India.(email: : mpdsimha@gmail.com)

Keerthi V Trimal, Department of Computer Science and Engineering, Vidyavardhaka College of Engineering, Mysuru, Karnataka India.

Adithi Krishnan, Department of Computer Science and Engineering, Vidyavardhaka College of Engineering, Mysuru, Karnataka India.

Karthik V, Department of Computer Science and Engineering, Vidyavardhaka College of Engineering, Mysuru, Karnataka India. advanced k-means clustering algorithm for object detection and recognition, which at least to some extent alleviates the disadvantages of the algorithm.

\section{RELATED WORKS}

Shaoqing et al.,[1] used the Region Proposal algorithm to create the Region Proposal Network. This reduces the operating time of the detection network. The simulated prediction of object boundaries and object scores is done at each position. Gavrila et al.,[2] used template hierarchy to capture the variety of object shapes and offline generation for a given shape distribution. Speed is increased and the method is more efficient than brute force.

Keivani et al.,[3] Pre-processing and removal of noise to extract feature points on the frame later, motion direction and motion magnitude are calculated and a number of moving objects are finally extracted. This method is faster and more accurate and works better when different types of objects are in the scene. Duan et al.,[4] description of each pixel is taken on a timeline and data is separated into several clusters by iterative fitness determination and moving GKA-based target detection. This provides a good visual effect and validation while dealing with a stable background.

Garima et al, [5] have used image histogram and histogram normalization for classifying and segmenting the image using k-means. As the noise removal technique is used the efficiency in predicting and detecting the region of the brain tumor.

Rajput et al, [6] have eliminated the noise and later blood vessels network to facilitate the detection of optic dye and later classified based on energy and threshold. OD has been eliminated with an accuracy of $100 \%$ and increased efficiency.

Himanshu et al, [7] have used neoteric image segmentation technique and a color image is converted into Lab in various computational steps. Then segmentation of nuclei into the separate image is done by recalling $\mathrm{L}$ layer. There is a clear depiction of segmentation of complex colored medical images is obtained.

Ramesh et al, [8] have used both k-means and Median filtering for fast retrieval of raindrops. The drops are identified using shape modeling. The proposed system is fast compared to alternate droplet identification schemes.

Hyung et al, [9] have used a pattern of slopes between two points, k-means and least square method. Noise filtering and line extraction algorithms are used. We get the void

Published By: 
information for controlling the angular velocity of moving the robot through a vision system.

Yuan et al, [10] k-means algorithm are combined with the difference between a and b components in Lab color space to discern the cicatrices in leaf image. Easy detection of disease and a lot of time and manpower is saved.

Kan et al, [11] have used k-means for clustering the pixels in the target area. Using the background color both target and search area are defined. The performance was really high when this method was put to practical usage.

Tse e al, [12] have modeled the temporal distribution in the RGB domain for each spatial position and the object mask generation process integrates noise cancellation. Hence, satisfying object marks are obtained. Results obtained are good even when it is applied on the low-frame rate and noisy video sequences in which temporal tracking becomes impossible.

\section{COMPARISON OF DIFFERENT CONVEX CLUSTERING IN OBJECT DETECTION\& RESULTS}

The following table 1 gives us an idea of the different methods used in the field of convex clustering by different authors. It also illustrates some of the recommendations that we thought could be implemented

Table 1. Comparison of different convex clustering in object detection

\begin{tabular}{|c|c|c|c|c|c|}
\hline $\begin{array}{c}\text { Ref. } \\
\text { No }\end{array}$ & Objective & Concept Used & Results/ Outcome & Advantage & Disadvantage \\
\hline$\# 1$ & $\begin{array}{l}\text { To minimize the } \\
\text { objective function } \\
\text { in convex } \\
\text { clustering }\end{array}$ & $\begin{array}{l}\text { Separate parameters, } \\
\text { accommodate } \\
\text { missing data and } \\
\text { support prior } \\
\text { information on } \\
\text { relationships. }\end{array}$ & $\begin{array}{l}\text { Successfully } \\
\text { implemented with } \\
\text { maximum speed } \\
\text { achieved on ATI or } \\
\text { NVidia GPUs. }\end{array}$ & $\begin{array}{l}\text { Allows large scale } \\
\text { parallelization. } \\
\text { Applicable to high } \\
\text { dimensional } \\
\text { problems. }\end{array}$ & $\begin{array}{l}\text { Execution time is more } \\
\text { when moving matrices } \\
\text { over slow I/O channels } \\
\text { for plotting. }\end{array}$ \\
\hline$\# 2$ & $\begin{array}{l}\text { To overcome } \\
\text { sensitivity to } \\
\text { initialization in the } \\
\text { gradient descent } \\
\text { method of EM } \\
\text { algorithm }\end{array}$ & $\begin{array}{l}\text { Find global optimum } \\
\text { for initialization using } \\
\text { a simple algorithm. } \\
\text { Apply rate-distortion } \\
\text { theory. }\end{array}$ & $\begin{array}{l}\text { A minimum value } \\
\text { for global optimum } \\
\text { is obtained for cost } \\
\text { function and RD } \\
\text { function is smooth, } \\
\text { convex and has a } \\
\text { monotonic } \\
\text { decrease. }\end{array}$ & $\begin{array}{l}\text { Useful in large } \\
\text { dataset problems } \\
\text { where mixture } \\
\text { models fail to give } \\
\text { consistent results. } \\
\text { Extendable to any } \\
\text { proximity data. }\end{array}$ & $\begin{array}{l}\text { Clusters split with an } \\
\text { increase in } \beta \text { value and } \\
\text { fluctuation in a number } \\
\text { of clusters is present. }\end{array}$ \\
\hline \#3 & $\begin{array}{l}\text { Precision } \\
\text { agriculture which } \\
\text { is the modern } \\
\text { farming technique } \\
\text { and the approach } \\
\text { used here. }\end{array}$ & $\begin{array}{l}\text { K nearest Neighbors } \\
\text { and naïve random tree } \\
\text { technique }\end{array}$ & $\begin{array}{l}\text { In this technique, it } \\
\text { was more } \\
\text { productive and } \\
\text { more profit and it } \\
\text { helped many to } \\
\text { plant the right crop } \\
\text { at the right time. }\end{array}$ & $\begin{array}{l}\text { The use of an expert } \\
\text { system and IoT is an } \\
\text { excellent way to } \\
\text { improve the crop } \\
\text { rate. }\end{array}$ & $\begin{array}{l}\text { The expert system does } \\
\text { tell about the herbicide } \\
\text { and pesticide } \\
\text { recommendation } \\
\text { depending on the } \\
\text { disease but the use of a } \\
\text { camera or an image } \\
\text { capturing device is used } \\
\text { in their paper. Also, } \\
\text { battery consumption } \\
\text { can be high. }\end{array}$ \\
\hline$\# 4$ & $\begin{array}{l}\text { Minimize the } \\
\text { objective function } \\
\text { of convex } \\
\text { clustering. }\end{array}$ & $\begin{array}{l}\text { Two splitting } \\
\text { methods = ADMM } \\
\text { and AMA are } \\
\text { introduced and tested } \\
\text { on datasets. }\end{array}$ & $\begin{array}{l}\text { Both ADMM and } \\
\text { AMA lead to less } \\
\text { computation time } \\
\text { compared to sub } \\
\text { gradient method. }\end{array}$ & $\begin{array}{l}\text { Storage required and } \\
\text { computation time is } \\
\text { less for both ADMM } \\
\text { and AMA compared } \\
\text { to other methods. }\end{array}$ & $\begin{array}{l}\text { ADMM did not do as } \\
\text { well as AMA because } \\
\text { of a large performance } \\
\text { gap. }\end{array}$ \\
\hline$\# 5$ & $\begin{array}{l}\text { Obtain cluster by } \\
\text { solving the convex } \\
\text { optimization } \\
\text { problem, efficiently } \\
\text { construct solution } \\
\text { path. }\end{array}$ & $\begin{array}{l}\text { Apply regularization } \\
\text { constant as shrinkage } \\
\text { term taking Iris } \\
\text { dataset for } \\
\text { illustration. }\end{array}$ & $\begin{array}{l}\text { The method can } \\
\text { clearly discriminate } \\
\text { the three classes in } \\
\text { the dataset from the } \\
\text { clustering } \\
\text { tree(solution path). }\end{array}$ & $\begin{array}{l}\text { Efficient for very } \\
\text { large datasets. }\end{array}$ & $\begin{array}{l}\text { Using the } 2 \text { norm } \\
\text { method, the results } \\
\text { cannot be interpreted as } \\
\text { a form of clustering. }\end{array}$ \\
\hline$\# 6$ & $\begin{array}{l}\text { To solve the } \\
\text { problem of } \\
\text { applying convex } \\
\text { clustering to a large } \\
\text { scale/ large dataset. }\end{array}$ & $\begin{array}{l}\text { The present } \\
\text { semi-smooth Newton } \\
\text { conjugate gradient } \\
\text { method is modified } \\
\text { by enforcing } \\
\text { appropriate stopping } \\
\text { criterion. }\end{array}$ & $\begin{array}{l}\text { The efficiency of } \\
\text { the algorithm for } \\
\text { large datasets is } \\
\text { high. }\end{array}$ & $\begin{array}{l}\text { Performance is high } \\
\text { and the algorithm is } \\
\text { extensible compared } \\
\text { to existing methods. }\end{array}$ & $\begin{array}{l}\text { Not generalized to } \\
\text { handle kernel based } \\
\text { convex clustering } \\
\text { models. }\end{array}$ \\
\hline
\end{tabular}




\begin{tabular}{|c|c|c|c|c|c|}
\hline \#7 & $\begin{array}{l}\text { To overcome } \\
\text { distortion that } \\
\text { occurs in convex } \\
\text { clustering when } \\
\text { uninformative } \\
\text { features are } \\
\text { included. }\end{array}$ & $\begin{array}{l}\text { Assume feature } \\
\text { vectors are centered, } \\
\text { incorporate adaptive } \\
\text { group-lasso penalty } \\
\text { into convex clustering } \\
\text { objective function. }\end{array}$ & $\begin{array}{l}\text { Performs better } \\
\text { than k-means } \\
\text { algorithm when } \\
\text { p>=500. Improved } \\
\text { accuracy of convex } \\
\text { clustering by } 45 \% \text {. }\end{array}$ & $\begin{array}{l}\text { S-AMA is } \\
\text { computationally } \\
\text { faster. Convex } \\
\text { clustering can also } \\
\text { be extended to } \\
\text { sparse convex } \\
\text { biclustering. }\end{array}$ & $\begin{array}{l}\text { Selection of weights } \\
\text { and tuning parameters } \\
\text { is difficult when } \\
\text { applied practically. }\end{array}$ \\
\hline \#8 & $\begin{array}{l}\text { To provide a } \\
\text { solution to } \\
\text { piecewise constant } \\
\text { Mumford-Shah } \\
\text { Problem. }\end{array}$ & $\begin{array}{l}\text { A finite number of } \\
\text { candidates is } \\
\text { specified. } \\
\text { Reformulate the } \\
\text { problem by lifting } \\
\text { and then apply } \\
\text { convex relaxation. }\end{array}$ & $\begin{array}{l}\text { Solution to the } \\
\text { given convex and } \\
\text { non-convex } \\
\text { problem is found } \\
\text { and hence the } \\
\text { global solution to } \mathrm{k} \\
\text { means problem is } \\
\text { found. }\end{array}$ & $\begin{array}{l}\text { Performs better in } \\
\text { Color Image } \\
\text { Quantization and } \\
\text { Image segmentation. }\end{array}$ & $\begin{array}{l}\text { Fails in the } \\
\text { implementation of } \\
\text { parrot case of image } \\
\text { segmentation where no } \\
\text { rounding procedure is } \\
\text { present. }\end{array}$ \\
\hline \#9 & $\begin{array}{l}\text { Modeling } \\
\text { chromatic objects } \\
\text { such as images etc. }\end{array}$ & $\begin{array}{l}\text { Extract colors, } \\
\text { transform colors to } \\
\text { color space, perform } \\
\text { convex clustering, set } \\
\text { a number of clusters, } \\
\text { output model. }\end{array}$ & $\begin{array}{l}\text { A modeled } \\
\text { chromatic object of } \\
\text { the given input is } \\
\text { obtained. }\end{array}$ & $\begin{array}{l}\text { The chromatic } \\
\text { model can be used } \\
\text { for image retrieval, } \\
\text { color transfer or } \\
\text { classification since } \\
\text { Nc is the output of } \\
\text { clustering. }\end{array}$ & N/A \\
\hline$\# 10$ & $\begin{array}{l}\text { Reduce time and } \\
\text { memory to learn } \\
\text { from datasets in } \\
\text { Q-learning. }\end{array}$ & $\begin{array}{l}\text { Incorporates convex } \\
\text { clustering to find } \\
\text { regions with the same } \\
\text { reward attribution } \\
\text { property. }\end{array}$ & $\begin{array}{l}\text { The proposed } \\
\text { method results in } \\
\text { faster convergence } \\
\text { than conventional } \\
\text { Q-learning } \\
\text { methods. }\end{array}$ & $\begin{array}{l}\text { A number of } \\
\text { iterations required to } \\
\text { reach goal state is } \\
\text { less. Suitable for } \\
\text { visual tracking } \\
\text { applications. }\end{array}$ & N/A \\
\hline$\# 11$ & $\begin{array}{l}\text { Derive solution that } \\
\text { explains given } \\
\text { examples in view } \\
\text { of the object of } \\
\text { interest. }\end{array}$ & $\begin{array}{l}\text { Applying convex } \\
\text { regularize on } \\
\text { stochastic gradient } \\
\text { descent approach. }\end{array}$ & $\begin{array}{l}\text { Shown that the } \\
\text { method is } \\
\text { applicable for } \\
\text { multi-view spectral } \\
\text { clustering apart } \\
\text { from increased } \\
\text { performance. }\end{array}$ & $\begin{array}{l}\text { Highly scalable. } \\
\text { Increase in a number } \\
\text { of examples doesn't } \\
\text { need computing full } \\
\text { gradient. }\end{array}$ & $\begin{array}{l}\text { NMI value for Caltech } \\
250 \text { dataset is less when } \\
\text { compared to other } \\
\text { methods. }\end{array}$ \\
\hline$\# 12$ & $\begin{array}{l}\text { To estimate the } \\
\text { direction of arrival } \\
\text { of sound and } \\
\text { distance of a 3D } \\
\text { sound source. }\end{array}$ & $\begin{array}{l}\text { FISTA to formulate } \\
\text { the problem, optimize } \\
\text { and post-process it, } \\
\text { dictionary coherence } \\
\text { and generate } \\
\text { monopole dictionary, } \\
\text { adjust monopoles and } \\
\text { apply primal-dual } \\
\text { splitting. }\end{array}$ & $\begin{array}{l}\text { Performance } \\
\text { against the MUSIC } \\
\text { method was much } \\
\text { higher. }\end{array}$ & $\begin{array}{l}\text { Found that this } \\
\text { method could also be } \\
\text { applied to the special } \\
\text { discretization of the } \\
\text { sound field. }\end{array}$ & $\begin{array}{l}\text { Some spurious } \\
\text { components remained } \\
\text { while tracking distance } \\
\text { when the experiment } \\
\text { was performed in the } \\
\text { anechoic chamber. }\end{array}$ \\
\hline
\end{tabular}

\section{CONCLUSION}

Clustering is one of the key data mining techniques. Data mining has many applications in different fields, one of which is image processing. Visual information is the most important information that the human brain perceives, processes and interprets. As a computer-based technology, digital image processing has applications in a variety of fields, such as medical/biological image processing, space image processing, etc. After reviewing papers on image processing, image segmentation, and clustering, we concluded that hierarchical clustering, clustering of k-means, convex clustering, etc. each has its own advantages and disadvantages. A detailed study of convex clustering papers revealed a few disadvantages in convex clustering. Our plan is to create a new algorithm that combines features of various clustering algorithms with convex clustering and to some extent omits its drawbacks.

\section{ACKNOWLEDGMENT}

The authors express gratitude towards the assistance provided by Accendere Knowledge Management Services Pvt. Ltd. in preparing the manuscripts. We also thank our mentors and faculty members who guided us throughout the research and helped us in achieving the desired results. 


\section{REFERENCES}

1. S. Ren, K. He, R. Girshick, and J. Sun, "Faster R-CNN: Towards Real-Time Object Detection with Region Proposal Networks," IEEE Trans. Pattern Anal. Mach. Intell., vol. 39, no. 6, pp. 1137-1149, Jun. 2017.

2. D. M. Gavrila and V. Philomin, "Real-time object detection for "smart" vehicles," in Proceedings of the Seventh IEEE International Conference on Computer Vision, 1999, pp. 87-93 vol.1.

3. A. Keivani, J.-R. Tapamo, and F. Ghayoor, "Motion-based moving object detection and tracking using automatic K-means," in 2017 IEEE AFRICON, 2017, pp. 32-37.

4. Duan Xiuman, Sun Guoxia, and Yang Tao, "Moving target detection based on Genetic K-means Algorithm," in 2011 IEEE 13th International Conference on Communication Technology, 2011, pp. 819-822.

5. G. Singh and M. A. Ansari, "Efficient detection of brain tumor from MRIs using K-means segmentation and normalized histogram," in 2016 1st India International Conference on Information Processing (IICIP), 2016, pp. $1-6$.

6. G. G. Rajput and P. N. Patil, "Detection and Classification of Exudates Using K-Means Clustering in Color Retinal Images," in 2014 Fifth International Conference on Signal and Image Processing, 2014, pp. 126-130.

7. H. Yadav, P. Bansal, and R. KumarSunkaria, "Color dependent K-means clustering for color image segmentation of colored medical images," in 2015 1st International Conference on Next Generation Computing Technologies (NGCT), 2015, pp. 858-862.

8. M. R. Kanthan and S. N. Sujatha, "Rain drop detection and removal using K-Means clustering," in 2015 IEEE International Conference on Computational Intelligence and Computing Research (ICCIC), 2015, pp. 1-5.

9. Hyung-Suk Lho, Ji-Wook Kwon, Dongkyoung Chwa, and Suk-Kyo Hong, "Vision-based corridor line detection using k-means algorithm," in 2007 International Conference on Control, Automation and Systems, 2007, pp. 1052-1056.

10. Y. Liu, S. Zhou, and J. Sun, "Detection of Ginseng leaf cicatrices base on K-means clustering algorithm," in 2017 10th International Congress on Image and Signal Processing, BioMedical Engineering and Informatics (CISP-BMEI), 2017, pp. 1-5.

11. K.-I. Koyama, Y. Hamamoto, H. Kano, and Haiyuan Wu, "K-means tracker-based object tracking method for digital camera," in 2010 Digest of Technical Papers International Conference on Consumer Electronics (ICCE), 2010, pp. 43-44.

12. T.-W. Chen, S.-C. Hsu, and S.-Y. Chien, "Robust Video Object Segmentation Based on K-Means Background Clustering and Watershed in Ill-Conditioned Surveillance Systems," in Multimedia and Expo, 2007 IEEE International Conference on, 2007, pp. 787-790. 